\title{
Tumor formation on the coral Montipora informis
}

\author{
Hideyuki Yamashiro ${ }^{1, *}$, Miwa Yamamoto ${ }^{2}$, Robert van Woesik ${ }^{2}$ \\ ${ }^{1}$ Radioisotope Laboratory and ${ }^{2}$ Department of Chemistry, Biology and Marine Science, University of the Ryukyus, \\ Nishihara, Okinawa 903-0213, Japan
}

\begin{abstract}
A high incidence of tumors (i.e., abnormal skeletal growth) was observed on Montipora informis Bernard, 1897 (Acroporidae) coral colonies on the shallow reef flat of Sesoko Island, Okinawa, Japan. Tumors were recognized as slightly hemispherical protuberances and were characterized by fewer numbers of polyps per surface area, fewer zooxanthellae per polyp, and finer skeletal structures than normal. In addition, fecundity was significantly reduced in tumored areas. Tumor formation appeared localized, stable and non-epidemic. During the summer of 1998, coincident with the global coral bleaching event, tumored tissue suffered higher mortality than normal tissue. The mechanism triggering tumor formation remains unknown.
\end{abstract}

KEY WORDS: Coral $\cdot$ Tumors $\cdot$ Abnormal growth $\cdot$ Bleaching $\cdot$ Montipora informis $\cdot$ Reproduction

\section{INTRODUCTION}

Abnormal skeletal growths on coral colonies have been reported for at least $20 \mathrm{yr}$ in both the Indo-Pacific and Atlantic provinces (Cheney 1975, Bak 1983, Loya et al. 1984, Nishihira \& Veron 1995, Coles \& Seapy 1998). Tumors seem to develop from tissues and not as a consequence of interference by macro-organisms. Microbial causative agents are possible (Peters et al. 1986), but their generality is unconfirmed. Moreover, the effect of tumors on a coral's life history is rarely investigated. The present study characterizes tissue and skeletal differences and the reproductive capacity of tumors on the scleractinian coral Montipora informis. A global coral bleaching event in 1998 also allowed us to compare the susceptibility of tumored and nontumored $M$. informis colonies to elevated sea-surface temperatures (SSTs).

\section{MATERIALS AND METHODS}

Field methods. Encrusting Montipora informis colonies were studied in a $50 \times 50 \mathrm{~m}$ experimental plot, between 0.5 and $2 \mathrm{~m}$ below the low water datum, on the reef flat adjacent to the Sesoko Island Tropical Bio-

\footnotetext{
•E-mail: hyama@eve.u-ryukyu.ac.jp
}

sphere Research Center $\left(26^{\circ} 38^{\prime} \mathrm{N}, 127^{\circ} 52^{\prime} \mathrm{E}\right) . \mathrm{M}$. informis colonies in this study did not emerge during low spring tides. Within the experimental plot, underwater photographs were taken of 20 randomly selected colonies both with $(n=13)$ and without $(n=7)$ tumors on 22 June 1998. To assess the horizontal growth of tumors, 16 tumors from 5 colonies were also photographed on 28 March and on 22 June 1998. By nailing numbered tags near to each colony we were able to relocate colonies, and additional photographs were taken on 25 August, 1 October and 25 December 1998. Four coral samples with tumors and 4 coral samples without tumors were collected from colonies outside the experimental plot to characterize tissue and skeletal differences.

Laboratory analysis. Projected surface areas of live tissue, dead tissue and tumors were calculated from photographs that were scanned into a personal computer and analysed using $\mathrm{NIH}$ image analysis software. The size of each tumor was also expressed as mean diameter. The surface areas of the samples were calculated, and the densities of polyps and reticulum papillae were measured under a dissecting microscope. The samples were then decalcified in a solution of $10 \%$ acetic acid and $10 \%$ formalin, washed with tap water for $3 \mathrm{~h}$, and homogenized. The numbers of zooxanthella cells in the tumored and normal tissues were counted under a light microscope using a haemocy- 

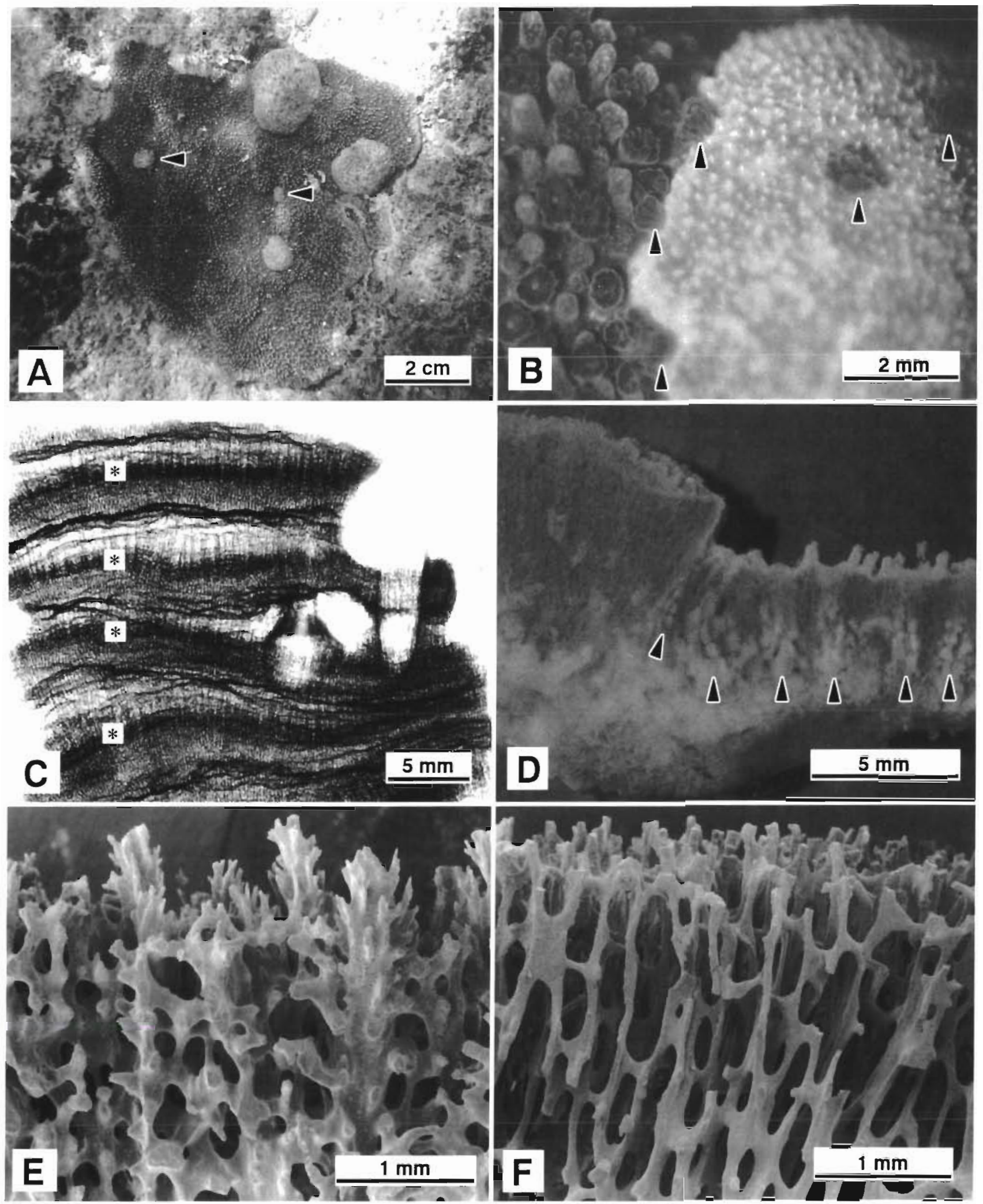

Fig. 1 Montipora informis. (A) Photograph of a colony supporting 5 tumors; the 2 small tumors are indicated by arrowheads (B) An enlarged image of a tumor (right) showing fewer polyps (arrowheads) than 'normal' tissue (left). Columnar structures around the normal tissue are reticulum papillae. (C) An X-radiograph of a skeletal vertical-section of a tumor, where asterisks indicate periodic (annual) density bands. The narrow, dense horizontal bands are dissepiments. Less-dense elliptical holes were made by boring bivalves. The mean growth rate of the 4 colonies was $7.4 \pm 0.2 \mathrm{~mm} \mathrm{yr}^{-1}$ (D) Decalcified tissue showing normal tissue with oocytes (arrowheads) (right) and tumored tissue without oocytes (left). (E, F) Scanning electron micrographs of (E) normal skeleton and $(\mathrm{F})$ tumored skeleton 
tometer and expressed as the number of cells per surface area of tissue.

Seven additional colonies supporting tumors were selected from the study plot to examine reproductive potential of oocytes. Three normal and 3 tumored samples were collected from each colony on 10 May, 9 June and 9 July 1998. Formalin-fixed samples were decalcified in the same manner as mentioned above, and then 21 randomly selected polyps (for each sample) were dissected (under a dissecting microscope) to record oocyte formation. Histological sections were prepared for corals collected on 9 June 1998; decalcified soft tissues were dehydrated in a graded series of butanol, embedded in paraffin, cut into $10 \mu \mathrm{m}$ slices, stained with eosin/hematoxylin and observed under a light microscope.

For skeletal density comparisons, 5 coral skeletons were cut with a diamond saw (Exakt cutting and grinding system). Resultant slabs were dried in a dessicator in vacuo and weighed using a chemical balance. To estimate annual linear extension rate of the tumors, four $5 \mathrm{~mm}$ thick tumorous skeletons were cut vertically with a handsaw, then $\mathrm{X}$-rayed at $30 \mathrm{kV}$ (Softex CMB) Five coral specimens were immersed in $1 \%$ commercial hypochlorite solution to remove soft tissues washed, air-dried, coated with gold in an ion coater and observed under a scanning electron microscope (Hitachi S-530).

\section{RESULTS}

One third of the Montipora informis colonies in the experimental plot supported tumors. Tumors appeared to randomly emerge from the coralla, but were also found on the growing edge. Their pale color and their hemispherical projection above the coralla (Fig. 1A,B) clearly distinguished the tumors on the colonies. Small tumors were circular or elliptical, while large tumors had irregular shapes. Although calyx and polyp structures exhibited no marked differences between tumored and normal coralla, tumors supported fewer polyps and fewer zooxanthellae per unit surface area than normal coralla (Table 1).

Tissue was continuous between normal and tumorous tissue, and tumors appeared to spread over rather than overgrow the underlying tissue. Spreading tumors swelled adjacent tissue, masking the corallite structures (Fig. 1B,D). Cross sections of tumors showed incomplete polyps, maintaining only mesenteries and mesenterial filaments that were disordered in size and arrangement. These buried and less-developed polyps were apparent even though no polyps were visible at the surface. The reticulum papillae on tumors were suppressed and trabeculae were finer than in nontumored skeletons (Fig, 1E,F). Parasitic micro- and macro-organisms such as trematodes, infesting algae or other unusual boring organisms were not observed in light-microscope observations.

The number of tumors per colony ranged from 2 to 31 $(8.46 \pm 2.28$, mean $\pm \mathrm{SE})$; their diameters ranged from 0.5 to $14 \mathrm{~cm}$ (Fig, 2), and their projected surface areas ranged from $0.17 \mathrm{~cm}^{2}$ to $159.6 \mathrm{~cm}^{2}$. During the study period we witnessed fusion of 3 adjacent tumors, and 2 tumors appeared to revert to normal (evidenced by their color and polyp densities) (Table 2). Tumors $(n=16)$ showed monthly horizontal extension rates of $0.97 \pm 0.12 \mathrm{~mm}$ (mean $\pm \mathrm{SE}$, range $=0.37$ to $1.77 \mathrm{~mm}$ ) Vertical annual growth rates of tumors $(n=8)$ by $X$ radiography was $7.4 \pm 0.2 \mathrm{~mm}$ (mean $\pm \mathrm{SE}$, range $=6.8$ to $8.4 \mathrm{~mm}$ ). We note that normal skeletal growth showed no density bands. The linear extension rate of tumors was independent of initial tumor diameter (simple linear regression, $p=0.538$ ), although there was a

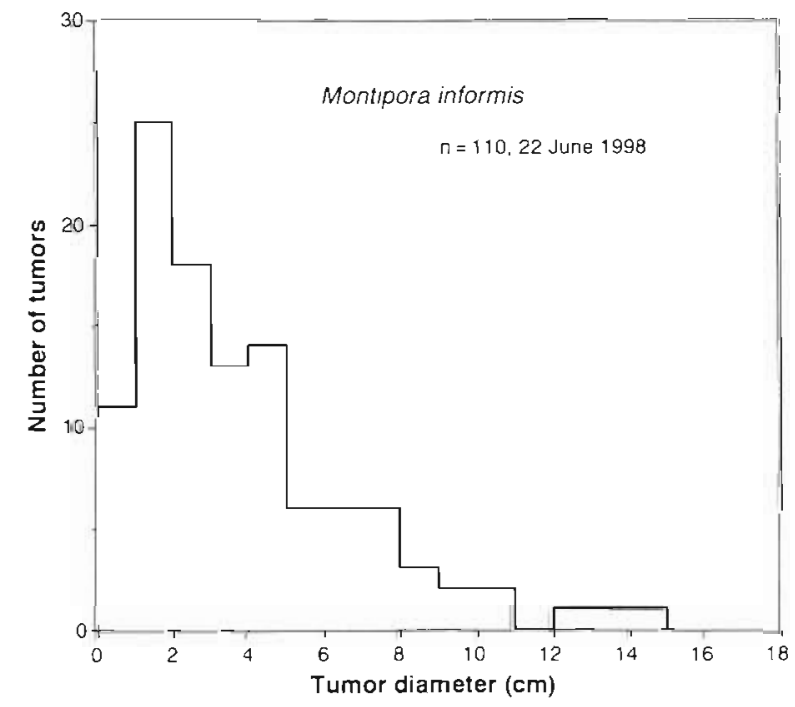

Fig. 2. Montipora informis. Size distribution of tumors on 13 colonies. Tumor diameters were calculated as mean diameters based on projected areas 
Table 2. Montipora informis. Changes in the number of tumors on colonies between the 4 observation times in 1998

\begin{tabular}{|c|c|c|c|c|c|}
\hline & \multirow[t]{2}{*}{$\begin{array}{l}\text { No. of live } \\
\text { colonies }\end{array}$} & \multicolumn{2}{|c|}{$\begin{array}{l}\text { No. of tumors on } \\
13 \text { colonies }\end{array}$} & \multicolumn{2}{|c|}{$\begin{array}{l}\text { No. of tumors on } \\
1 \text { live colony }\end{array}$} \\
\hline & & Alive & Dead & Mean & Range \\
\hline June & 13 & 110 & 0 & 8.46 & $2-31$ \\
\hline August & 10 & $33^{a}$ & 74 & 3.33 & $0-8$ \\
\hline October & 7 & 9 & 98 & 1.29 & $0-3$ \\
\hline December & 0 & 0 & 107 & - & - \\
\hline
\end{tabular}

positive relationship between the initial and final tumor surface area $\left(Y=109.7 X^{-0.618}, \mathrm{r}^{2}=0.697, \mathrm{p}<\right.$ $0.001 j$.

In June, August and October, there was no significant correlation between colony size and the percentage of colony surface area supporting tumors (Spearman's rank correlation analysis). There was, however, a significant positive relationship between the percentage of tumored surface area and the percentage of dead surface area on the Montipora informis colonies (Fig. 3). In early October, about half of the colonies, both with and without tumors, died. The mortality was coincident with higher than average seasonal SSTs (Fig. 4). There was no significant difference in the survivorship of large colonies, either with or without tumors ( $p>0.05, \chi^{2}$ test); however, small colonies $\left(<2000 \mathrm{~cm}^{2}\right)$ with tumors were more likely to die than those without tumors $\left(\chi^{2}=6.20, p<0.05\right)$. Similarly, the changes in percentage of live coral tissue area were significantly higher in solitary tumors (Fig. 5).

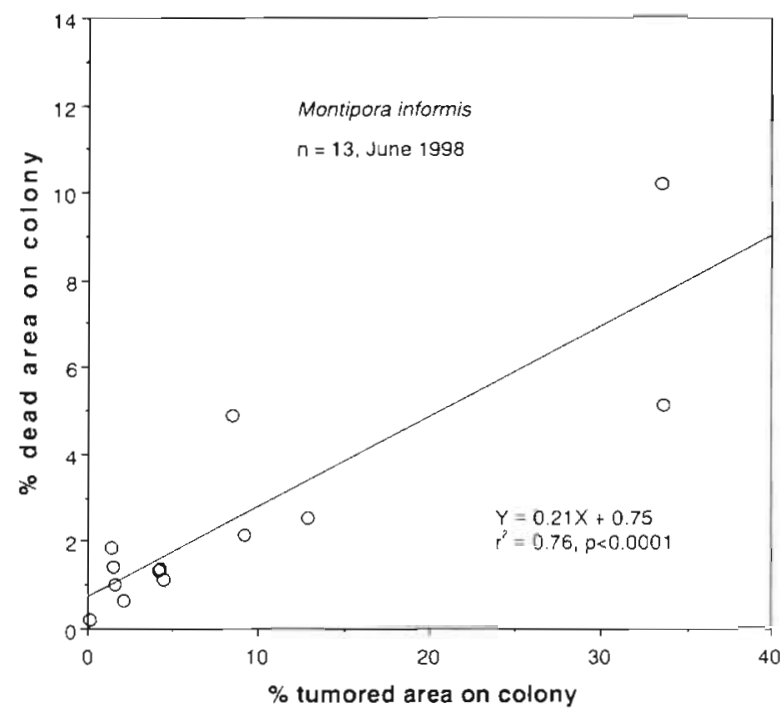

Fig. 3. Montipora informis. A linear regression showing the relationship between the percentage of the colony supporting tumors and the percentage of the colony with dead tissue

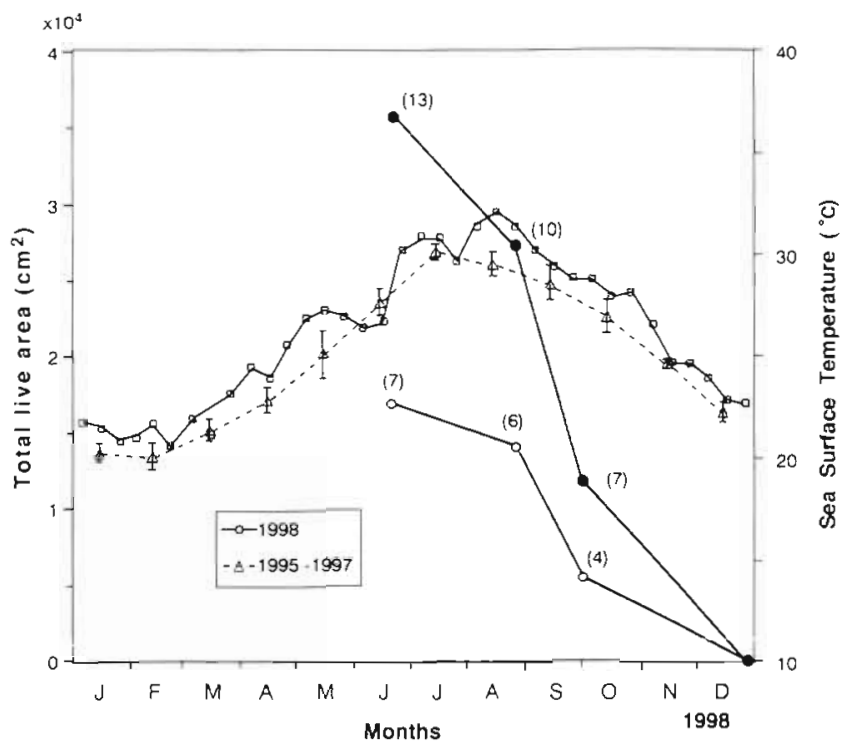

Fig. 4. Seasonal sea-surface temperatures (SSTs) and total coverage of alive Montipora informis colonies with $(\bullet)$ and without (O) tumors in 1998 at Sesoko Island. Numbers in parentheses show the number of colonies alive. SSTs from 1995 to 1997 are means \pm SD; data from Y. Nakano, Sesoko Station, Tropical Biosphere Research Center

Normal tissue collected on 9 June 1998 showed that $61 \%$ of the polyps $(61.1 \pm 8.8 \%$, mean $\pm \mathrm{SE}, \mathrm{n}=21)$ supported oocytes (Figs. 1D \& 6). Few fecund polyps

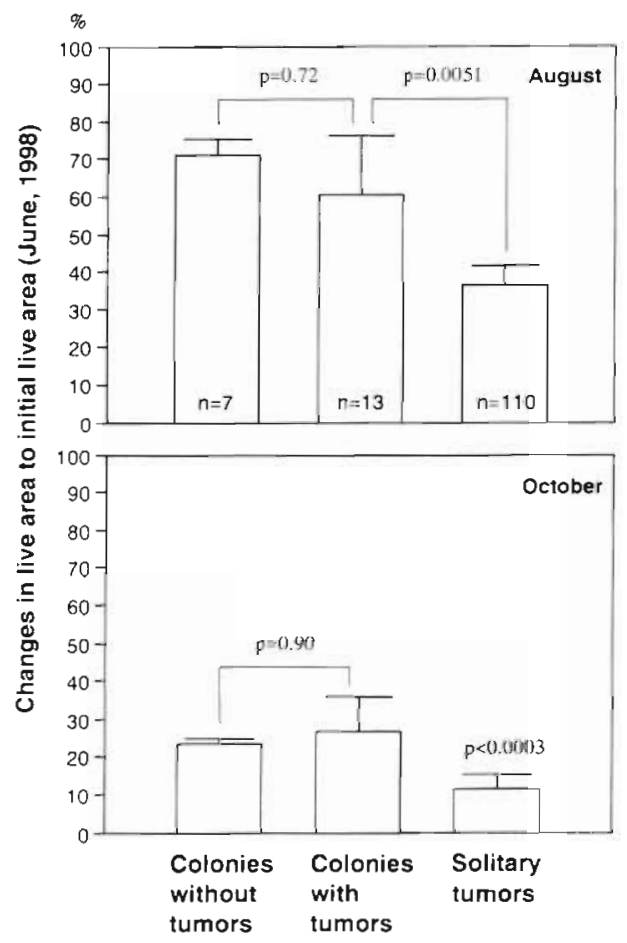

Fig. 5. Montipora informis. Changes in the percentage of live surface area compared to initial surface area, in June 1998. Note the susceptibility of tumored colonies. A Mann-Whitney $U$-test was used to obtain the p-value 


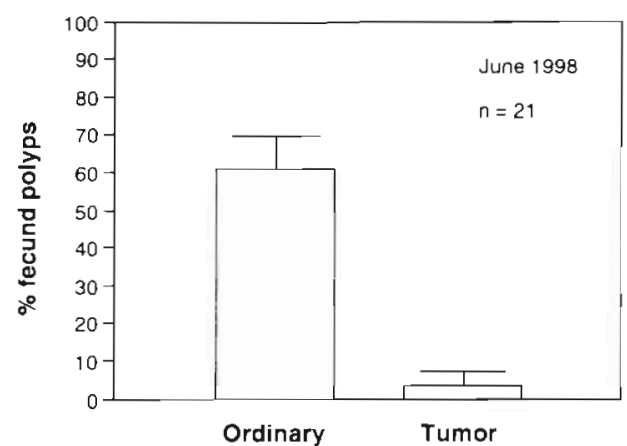

Fig. 6. Montipora informis. Fecundity of normal and tumored tissue on 9 June 1998

$(3.5 \pm 3.6 \%$, mean $\pm \mathrm{SE}, \mathrm{n}=21)$ were observed in tumored tissue and most oocytes were immature (Fig. 7); the difference in fecundity between tumored and normal tissue was significant ( $\mathrm{p}<0.0001$, Mann-Whitney $U$-test). Similar results were obtained for the corals collected on 10 May $(67.3 \pm 7.8 \%$ and $2.5 \pm 2.5 \%$, mean $\pm \mathrm{SE}$ ) and on 9 July in 1998 (54.5 $\pm 7.7 \%$ and $2.1 \pm 1.4 \%$, mean $\pm \mathrm{SE}$ ). In the final census in December 1998 all colonies had died.

\section{DISCUSSION}

Tumors on scleractinian corals have been reported for Acropora spp. from Guam, Enewetak, Curaçao, St. Croix, Puerto Rico and Oman (Cheney 1975, Bak 1983, Peters et al. 1986, Coles \& Seapy 1998), for Platygyra pini from the Great Barrier Reef (Loya et al. 1984) and for Porites spp. from Hawaii (Hunter \& Field 1997). The present study is the first description of tumors on Montipora informis. Tumored tissue supported fewer calices with fewer zooxanthellae, that is, pathological bleaching, which occurred abruptly at the transition boundary between ordinary and tumored tissues. These results agree with previous descriptions of tumored tissues (Cheney 1975, Bak 1983, Peters et al. 1986, Coles \& Seapy 1998).

Tumored skeletons were less dense than Montipora informis skeletons. Usually, the reticulum of $M$. informis is uniformly covered with elongated papillae (Veron \& Wallace 1984); however, the reticulum papillae in the tumored coralla were suppressed. Similarly, Acropora spp. with tumors tend to produce immersed corallites (Cheney 1975, Bak 1983, Peters 1984). The implications of this morphological differentiation are unclear, and we were unable to identify a causative agent.

It is interesting to note, however, the alternating density bands in the tumors (Fig. 1C), which are not unlike the 4 bands of varying density produced every year by Porites lutea from Thailand (Brown et al. 1986). These bands are not present in normal Montipora informis skeletons. This suggests a switch in growth mode from horizontal extension in normal $M$. informis coralla to vertical extension in tumors.

Loya et al. (1984) reported that large colonies had more tumors per unit mean colony diameter than small colonies, and suggested that large colonies were more likely to be affected by external damage. Here we show no relationships between colony size and the number of tumors. Since Montipora informis are encrusting colonies, they are more likely to undergo fission than massive Platygyra pini colonies as described by Loya et al. (1984). Frequent fission would possibly mask any relationship between colony size and tumor damage. Indeed, Fig. 3 shows a significant correlation between the percentage of tumored surface area and dead surface area; and partial colony mortality was clearly a consequence of higher than average SSTs, occurrent throughout the Indo-Pacific in the summer of 1998. Tumored colonies were noticeably more susceptible to elevated SSTs. Furthermore, Bak (1983) showed that tumors suppressed Acropora palmata growth, suggesting a negative energy drain to the tumor from adjacent tissue. We showed that small colonies $\left(<2000 \mathrm{~cm}^{2}\right)$ with tumors were more susceptible to bleaching than small colonies without tumors. In combination, these results suggest that tumor formation has negative effects on coral growth.

Hunter \& Field (1997) showed that oocyte diameters in tumors were similar to those in normal polyps, but the number of oocytes per gonad and the number of gonads per polyp were reduced. Loya et al. (1984) reported oocytes developing in both normal and tumored coralla on Platygyra pini colonies. In contrast, the present study found that most tumored polyps did not support oocytes, and when they did, the oocytes were immature. It is suggested that tumors on Montipora informis may be more pathological, in terms of their effect on reproductive capacity, than those on other coral species examined in other studies (Acropora, Porites and Platygyra species). The fate of immature oocytes was not determined because of the summer bleaching event and subsequent coral mortality.

Tumors have been observed on Montipora informis colonies within the study area at Sesoko Island since 1980 (K. Sakai pers. comm.), and would therefore appear to be localized, stable and non-epidemic. However, a high frequency of small tumors on these $M$. informis corals may imply 1 of the following 3 non-exclusive scenarios: (1) some of these tumors revert to normal, (2) the frequency of occurrence of tumors is increasing, or (3) many colonies die from the effects of the tumors, thereby eliminating them from the population census. Hypotheses relevant to these scenarios need further testing. 

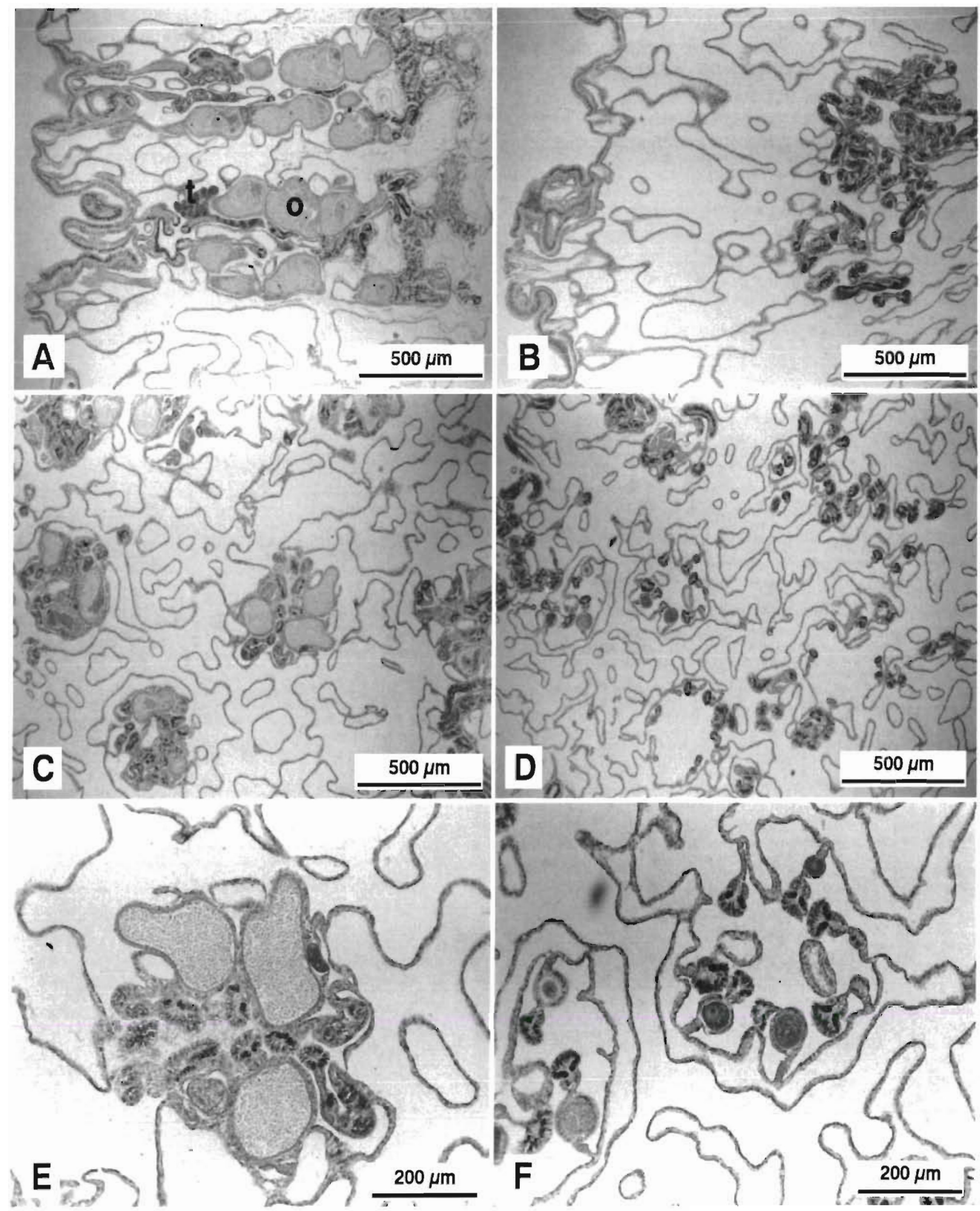

Fig. 7. Montipora informis. Histological sections of corals on June 1998. (A, C, E) 'Normal' tissue and (B, D, F) tumored tissue. Note that (A) and (B) are vertical sections, (C) and (D) are cross sections, and (E) and (F) are enlarged cross sections. t: testis; 0 : oocyte. Note that oocytes in tumored tissue are few and when present are immature 
Acknowledgements. We wish to thank K. Sakai from the Sesoko Station. Tropical Biosphere Research Center (TBRC), University of the Ryukyus, for stimulating discussions and Sandra van Woesik for editorial comments. This is a contribution of the TBRC

\section{LITERATURE CITED}

Bak RPM (1983) Neoplasia, regeneration and growth in the reef-building coral Acropora palmata. Mar Biol 77:221-227

Brown BE, Le Tissier M, Howard LS, Charuchinda M, Jackson JA (1986) Asynchronous deposition of dense skeletal bands in Porites lutea. Mar Biol 93:83-89

Cheney DP (1975) Hard tissue tumors of scleractinian corals. Adv Exp Med Biol 64:77-87

Coles SL, Seapy DG (1998) Ultra-violet absorbing compounds and tumorous growths on acroporid corals from Bandar

Editorial responsibility: Nicolaus Peters,

Hamburg, Germany
Khayran, Gulf of Oman, Indian Ocean. Coral Reefs 17: $195-198$

Hunter C, Field SN (1997) Characterization of tumors in Porites corals. Am Zool 37:55

Loya Y, Bull G, Pichon M (1984) Tumor formations in scleractinian corals. Helgol Meeresunters 37:99-112

Nishihira M, Veron JEN (1995) Hermatypic corals of Japan. Kaiyusha Publishers, Tokyo (in Japanese)

Peters EC (1984) A survey of cellular reactions to environmental stress and disease in Caribbean scleractinian corals. Helgol Meeresunters 37:113-137

Peters EC, Halas JC, McCarty HB (1986) Calicoblastic neoplasms in Acropora palmata, with a review of reports on anomalies of growth and form in corals. J Nat Cancer Inst 76:895-912

Veron JEN, Wallace CC (1984) Scleractinia of Eastern Australia. Part V. Family Acroporidae. Aust Inst Mar Sci Monogr Ser 4, Australian National Univ Press, Canberra

Submitted: September 24, 1999; Accepted: May 3, 2000 Proofs received from author(s): June 9, 2000 